\title{
Vertebroplasty in Osteoporotic Vertebral Fractures: Technical Considerations and Complications
}

\author{
Dhurvas R Ramprasath ${ }^{1}$, Vasudevan Thirunarayanan², Joseph David Vimal Kumar ${ }^{3}$, Arjun Rajan ${ }^{4}$, Kabilan Muthulingam $^{5}$
}

\begin{abstract}
Background: Osteoporosis is a global problem involving majority of elderly population. Vertebral compression fracture in this population leads to severe pain and decreased quality of life. Percutaneous vertebroplasty alleviates the pain, with a minimal invasive approach. The aim of our study was to analyze the technical considerations and complications of this surgery.

Materials and methods: Vertebroplasty was performed in 35 patients with male: female ratio 13:22 in the age group of 52-80 years. We used unipedicular needle insertion and injected $2-3 \mathrm{~mL}$ of high-viscosity polymethylmethacrylate in the fractured vertebral body. Visual analog score, Oswestry disability score, and Oswestry disability index were used to analyze functional outcome.

Results: Pain relief had a significant $p$ value $(<0.0001)$. Oswestry disability score and index showed a good improvement in the quality of life with a $p$ value $<0.0001$. The Beck index did not show a significant change postoperatively. Complications encountered were cement extravasation into venous pathway, cement extravasation into the soft tissue, cement extravasation into the needle tract, and adjacent vertebral fractures. No major complication was encountered.

Conclusion:Vertebroplasty provides better pain relief, improved function, and quality of life than conservative management. Use of an appropriate technique will improve the overall success rate of the procedure and minimize the complications.

Clinical significance: For patients with osteoporotic fractures who do not respond to conservative measures, vertebroplasty is a simple, effective, and minimally invasive procedure providing adequate pain relief and improving the quality of life.

Keywords: Adjacent vertebral fracture, Cement extravasation, Lollypop sign, Osteoporotic vertebral fractures, Percutaneous, Polymethylmethacrylate, Vertebroplasty.

Journal of Orthopedics and Joint Surgery (2020): 10.5005/jp-journals-10079-1018
\end{abstract}

\section{INTRODUCTION}

Osteoporosis is a systemic bone disorder characterized by a reduction in bone mass. Vertebral compression fracture occurs in approximately $20 \%$ of individuals over 70 years of age. ${ }^{1}$ The fractures can result in persistent pain, inability to perform daily activities, and a marked decrease in the quality of life. ${ }^{2,3}$ Reduction of pain and stabilization of vertebrae are the goals of treatment in vertebral compression fracture. ${ }^{2,3}$ Percutaneous vertebroplasty is a minimally invasive method involving injection of polymethylmethacrylate (PMMA) into the vertebral body to stabilize the fracture. ${ }^{4}$ Pain relief is usually observed within first 72 hours after treatment. ${ }^{5,6}$ There are concerns regarding procedural complications, which are mostly related to leakage of PMMA into adjacent structures, or injection into the vertebral venous plexus. ${ }^{7}$ Such venous leaks cause compression of the spinal cord or nerves or could also cause pulmonary embolism. ${ }^{5,8-10}$ The overall complication rate was reported to range from 1 to $10 \%$, with a higher incidence of complication in cases with the metastatic lesion. ${ }^{8}$ Several other surgical methods of treatment include balloon kyphoplasty, vertebroplasty combined with pedicle screw stabilization (hybrid procedure), cement augmented pedicle screw stabilization, decompression, and stabilization. The aim of our study was to analyze the technical consideration of vertebroplasty surgery and the possible complication arising out of vertebroplasty surgery.

\section{Materials and Methods}

Our study was an observational prospective study done from March 2012 to December 2013 in a tertiary care center. There were a total of 40 patients involving 15 males and 25 females in the age group
${ }^{1}$ Department of Orthopaedic Surgery, Chengalpattu Medical College Hospital (The TN Dr. MGR Medical University), Chengalpattu, Tamil Nadu, India

${ }^{2}$ Government Dharmapuri Medical College Hospital, Dharmapuri, Tamil Nadu, India

${ }^{3}$ Government Hospital, Vaniyambadi, Tamil Nadu, India

${ }^{4}$ Department of Trauma and Orthopaedics, Wrightington, Wigan and Leigh NHS Foundation Trust, Wigan, UK

${ }^{5}$ Institute of Orthopaedics and Traumatology, Coimbatore Medical College Hospital, Coimbatore, Tamil Nadu, India

Corresponding Author: Dhurvas R Ramprasath, Department of Orthopaedic Surgery, Chengalpattu Medical College Hospital (The TN Dr. MGR Medical University), Chengalpattu, Tamil Nadu, India, Phone: +91 9443464476, e-mail: dhurvasramprasath@gmail.com

How to cite this article: Ramprasath DR, Thirunarayanan V, Vimal Kumar JD, et al. Vertebroplasty in Osteoporotic Vertebral Fractures: Technical Considerations and Complications. J Orth Joint Surg 2020;2(1):17-21.

Source of support: Nil

Conflict of interest: None

of 52-80 years. Two patients had associated injuries, which were managed simultaneously.

Inclusion criteria consisted of (1) painful osteoporotic vertebral fracture more than 1 month old, refractory to conservative treatment; (2) progressive kyphosis more than $20^{\circ}$; (3) intact posterior cortex; (4) Kummel's disease; (5) malignant vertebral disease (metastasis/myeloma); and (6) vertebral hemangioma. 
Exclusion criteria consisted of (1) responding to conservative management, (2) infection, (3) coagulopathy, (4) posterior cortex breach, (5) cord compression, (6) neurological deficit, (7) vertebra plana; and (8) collapse more than $80 \%$.

A detailed systemic screening was done to rule out any malignancies including myeloma and any other pulmonary and cardiac ailments. Local spine tenderness was elicited and neurological examination was performed to identify any neurological deficit. Visual analog score (VAS), Oswestry disability score, and Oswestry disability index were recorded preoperatively and postoperatively. Radiological investigation consisted of X-ray spine AP, lateral views, and CT scan of the spine. The CT scan provided information regarding level of fracture, type of fracture, posterior cortex breach, percentage of collapse, involvement of superior and inferior end plate, percentage of spinal canal compression, pedicle fracture, and morphology.

\section{Operative Procedure}

All 40 cases were operated under IV sedation and local anesthesia and cardiac and respiratory monitoring. The patient was positioned prone on a radiolucent table. Positioning was done without the use of bolsters but with adequate padding of bony and soft tissue prominences. The image intensifier was positioned such that true AP and lateral views could be obtained. Under C-arm image intensifier guidance a small incision was made just lateral and superior to the cutaneous pedicle location. A Cooks needle (11 gauge/15 cm length) was introduced into the superolateral border of the pedicle (10 o'clock for the left and 2 o'clock for the right pedicle). During advancement of the needle, once the needle touched the medial cortex (in AP view), a lateral view was taken to confirm the entry of the needle into the vertebral body at its posterior border. Then the needle was advanced with gentle tapping using a mallet, into the vertebral body (under lateral view monitoring) until it reached the junction of anterior and middle onethird of the body. Vertebroplasty PMMA cement (Biomet) was mixed and loaded in 3-mL syringe. Once a toothpaste like consistency was seen (rat tailing) (Fig. 1), the cement was injected slowly into the vertebral body under AP and lateral monitoring using the C-arm image intensifier. During the process of injection, the needle was withdrawn until the junction of middle one-third and posterior onethird of the vertebral body was reached. Once $2.5 \mathrm{~mL}$ of cement was injected, the syringe was removed and the trocar was introduced into the cannula to drive the cement in the cannula into the

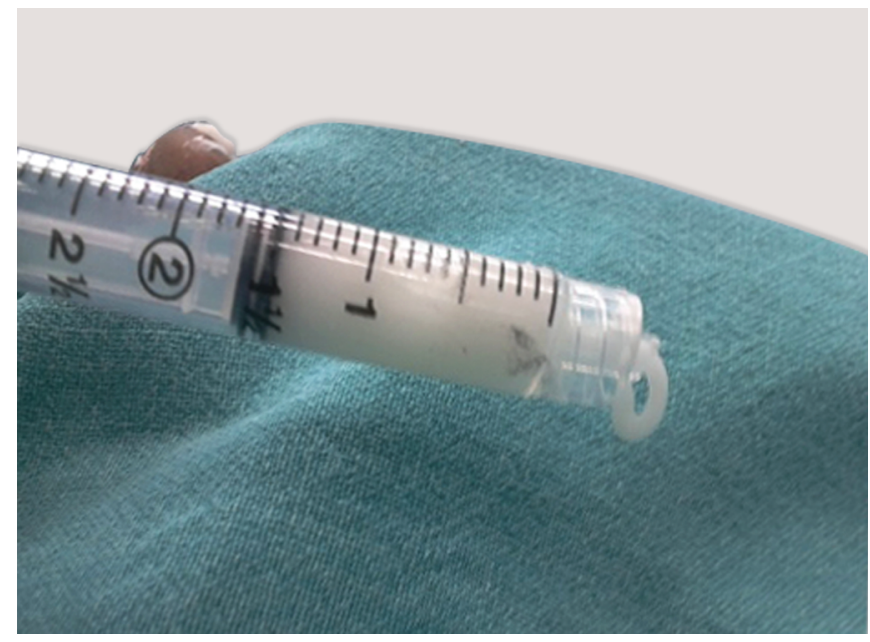

Fig. 1: Rat tailing of the cement indicating the ideal time for injection vertebral body. This was followed by gentle alternative clockwise and anticlockwise rotation of the needle with trocar in situ so that any continuity between the cement in the vertebral body and the needle tip will be broken (in the initial few cases, the cannula along with the cement within it was rotated clockwise and anticlockwise without introducing the trocar into the cannula). The patient was turned supine, once the cement was solidified.

\section{Postoperative Protocol}

Neurological examination was done and pain relief was assessed using VAS, Oswestry disability score, and index. Standard AP and lateral radiograph was taken to identify the extent of cement in the body, any extravasation into the vein, or adjacent structures and restoration of vertebral heights (Fig. 2).

Oral bisphosphonate was started along with other pharmacological agents like teriparatide and vitamin D supplementation if there was no contraindication to improve the overall bone quality. Care was taken to investigate the causes for recurrent falls and appropriate prevention methods were taken. The patient was mobilized from the first postoperative day without any brace support. The patient was followed up at 1-month, 3-month, 6-month, and 1-year interval.

\section{Results}

In our study, 40 patients underwent vertebroplasty at various vertebral levels (Table 1). Since five patients were lost for follow-up, 35 patients were considered for the statistical analysis. We had a minimal follow-up of 3 months and maximum follow-up of 18 months, with mean follow-up of 8 months.

The statistical analysis was done using the "Wilcoxon signedrank test with continuity correction" for PAIRED DATA and the "Wilcoxon rank-sum test with continuity correction" for UNPAIRED DATA. The results were given in terms of the $p$ value. The correlations were done using "linear regression," and the results were described with adjusted $R$-squared statistic, $F$-statistic, and $p$ value.

Preoperative scores, compared with postoperative scores at immediate, 1-month, 3-month, and 6-month postoperative had a $p$ value $<0.0001$ in all postoperative periods. This is statistically significant. Similarly, a significant reduction in analgesic uptake was observed. The patients without analgesics necessity increased from $0.5 \%(n=2)$ preoperative to $85.7 \%(n=30)$ at 6 months' follow-up ( $p<0.0001)$. The preoperative and postoperative Oswestry disability score and index at immediate, 1, 3, and 6 months showed a $p$ value $<0.0001$ in all postoperative periods.

We also observed that pain relief decreases as age increases (indicated by VAS), but the correlation was not statistically significant ( $p$-0.1266).

The average Beck index (anterior vertebral height/posterior vertebral height) was used to evaluate kyphosis. The preoperative Beck index was 0.83 and the immediate postoperative average Beck index was 0.84 . This shows no significant increase in the vertebral height due to vertebroplasty.

\section{Complications}

The complications encountered with vertebroplasty mainly concern cement leakage. We observed minor cement extravasation into soft tissue anteriorly in one patient. Also, we had one patient with minor cement extravasation into the venous channel (Fig. 3) and two patients with "Iollypop sign," which is the extravasation of cement into the needle tract having continuity with the cement in the vertebral body (Fig. 4). These complications with regard to 

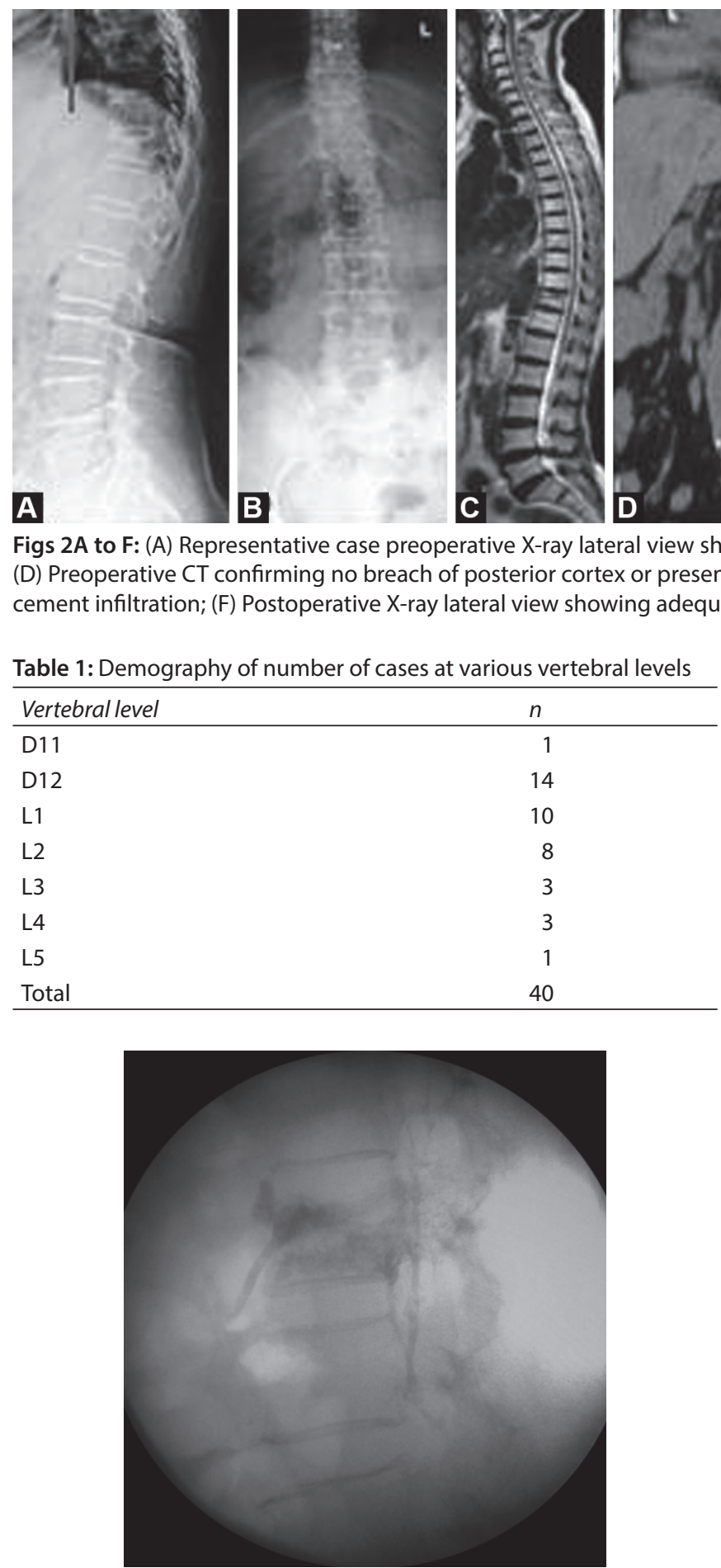

Fig. 3: Cement extravasation into the surroundings venous channels

extravasation can be prevented by proper timing of the injection procedure, so as to not inject it during the early liquid phase. The lollypop sign can be prevented by introducing the stillette and waiting for the setting of cement till the time where it does not retain continuity when withdrawn.

Leakage of cement can be prevented by proper examination of posterior cortical and pedicular integrity on the preoperative CT imaging. We also encountered adjacent cranial vertebral fracture (Fig. 5) in one patient. This is one of the known complications due to

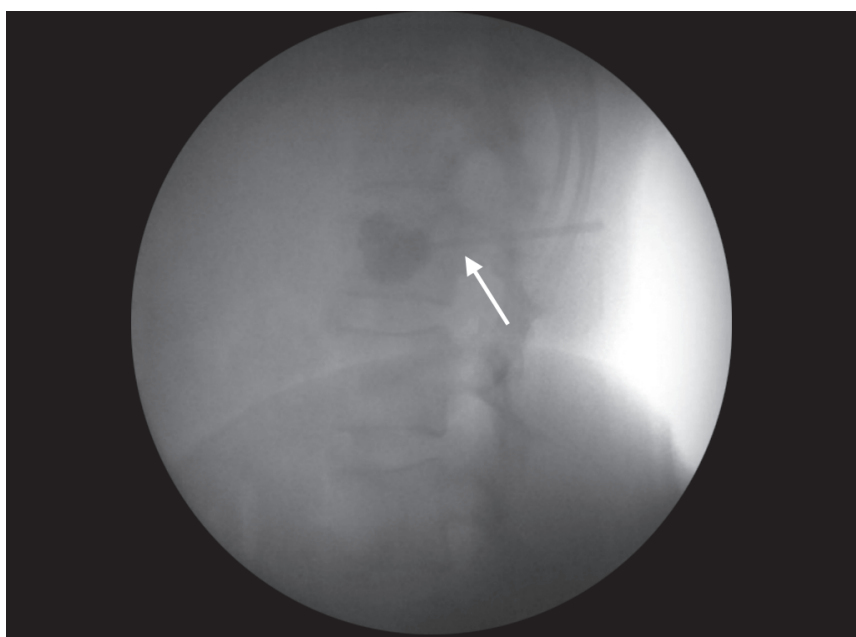

Fig. 4: "Lollypop sign" represented by solidification of cement in the needle tract (indicated by arrow)

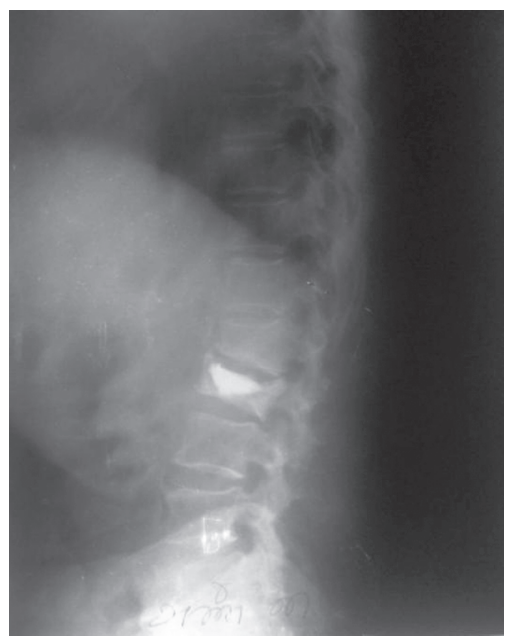

Fig. 5: Fracture is noted in the adjacent cranial vertebra 
increased stiffness of the spine at the level of the adjacent segment. Prevention of adjacent vertebral fracture can be done by avoiding excessive cement filling ( $>2 \mathrm{~mL}$ ) and avoiding injection of cement into disc space. One patient with multiple myeloma, who underwent vertebroplasty, did not have significant pain relief.

\section{Discussion}

Galibert and Deramond performed the first vertebroplasty in 1984 on a 54-year-old female patient with vertebral hemangioma of the C2 vertebra. After performing C2 laminectomy, the hemangioma was excised and vertebroplasty was done through the anterolateral approach. Subsequently, they performed vertebroplasty percutaneously in several patients and published their results in 1987. ${ }^{11}$ This was named as the "Deramond technique."

A meta-analysis by Yuan et al. ${ }^{12}$ indicates that overall percutaneous vertebroplasty and balloon kyphoplasty reduced pain and improved function and quality of life as compared with conservative treatment. In the same study, it was indicated that pain relief by vertebroplasty was greater than that of conservative management, whereas pain relief by kyphoplasty is similar to that of conservative management. Both procedures improved the functional outcome to a greater degree than conservative management. In our study also, there was reduction of pain and improvement of function and quality of life.

Balloon kyphoplasty seems to have better radiological outcome without, however, any clinical relevance. ${ }^{13}$ Balloon kyphoplasty has a longer operation time and higher material cost. Moreover, kyphoplasty provides less pain relief than vertebroplasty. ${ }^{12}$ Balloon kyphoplasty is specifically indicated for a recent ( $<7-10$ days) vertebral fracture with a kyphotic angle $>15^{\circ} .14,15$

Biomechanical studies demonstrated that cement filling of the vertebral body of $20 \%$ of vertebral body volume $(2-4 \mathrm{~mL})$ was accompanied by a $36 \%$ increase in the stiffness of the vertebral body. Cement injection of more than $20 \%$ vertebral body volume resulted in a significantly increased extravasation rate. ${ }^{16}$ The literature describes the extravasation rate with a wide range from 11 to $36 \%$. In our study, we have used $2-3 \mathrm{~mL}$ of high-viscosity PMMA and hence did not encounter any major extravasation. According to a recent update, ${ }^{17}$ the optimal volume of cement is still an ongoing area of research. ${ }^{18-20}$

In the VAPOUR study (the fixed double-blinded sham-controlled RCT to evaluate vertebroplasty exclusively in patients with vertebral compression fracture less than 6 weeks old), vertebroplasty resulted in a significantly improved general quality of life. ${ }^{21}$

In patients with multiple osteoporotic fractures, $68 \%$ fractures were at continuous levels, suggesting a strong trend toward "clustering" of fractures as part of natural history of osteoporosis. ${ }^{22}$ Meta-analysis has not found a risk of adjacent vertebral fracture after vertebroplasty. However, cement transfer to the adjacent intervertebral disc was identified as a predictor for the occurrence of secondary fractures. ${ }^{23}$ So, most of the studies do not consider prophylactic vertebroplasty to be justifiable.

Extravasation of cement into the needle tract is sometimes encountered. This may be due to premature removal of the needle before the cement is completely hardened or because of hardening of the cement retained inside the cannula of the needle. The later complication can be avoided by pushing the cement in the cannula into the vertebral body with the trocar. We have named this complication as "lollypop sign" in our study.
The technique of needle insertion decides the success rate of vertebroplasty. This includes intrapedicular trajectory, placement of tip of the needle in the vertebral body during cement injection, and avoidance of the lollypop sign. A detailed description of the technique is available in the review article by Kallmes et al. ${ }^{24}$

\section{CONCLUSION}

Vertebroplasty is a useful procedure to relieve pain and to improve function and quality of life in patients with osteoporotic vertebral fractures. All randomized controlled trials evaluating vertebroplasty found it to be superior to conservative treatment or placebo. Appropriate technical consideration including trajectory of the needle, use of high-viscosity PMMA, injection of cement not exceeding $3 \mathrm{~mL}$, and selecting patients with painful osteoporotic fractures will result in a less complication rate and good functional outcome.

\section{Clinical Significance}

For patients with osteoporotic fractures who do not respond to conservative measures, vertebroplasty is a simple, effective, and minimally invasive procedure providing adequate pain relief and improving the quality of life. This is particularly useful in patients where pedicle screw stabilization may lead to increased morbidity due to the procedure itself and complications like screw pull out.

\section{References}

1. Cohen LD. Fractures ofthe osteoporotic spine. Orthop Clin North Am 1990;21(1):143-150.

2. Lamy O, Uebelhart B, Aubry-Rozier B. Risks and benefits of percutaneous vertebroplasty or kyphoplasty in the management of osteoporotic vertebral fractures. Osteoporos Int 2014;25(3):807-819. DOI: 10.1007/s00198-013-2574-4.

3. Silverman SL. The clinical consequences of vertebral compression fracture. Bone 1992;13:S27-S31. DOI: 10.1016/8756-3282(92)90193-Z.

4. Teyssédou S, Saget M, Pries P. Kyphopasty and vertebroplasty. Orthop Traumatol Surg Res 2014;100(1 Suppl):S169-S179. DOI: 10.1016/ j.otsr.2013.11.005.

5. Cotten A, Boutry N, Cortet B, et al. Percutaneous vertebroplasty: State of the art. Radiographics 1998;18(2):311-320. DOI: 10.1148/ radiographics.18.2.9536480; discussion,320-323.

6. Deramond H, Depriester C, Galibert P, et al. Percutaneous vertebroplasty with polymethylmethacrylate. Technique, indications, and results. Radiol Clin North Am 1998;36(3):533-546. DOI: 10.1016/ s0033-8389(05)70042-7.

7. Martin JB, Jean B, Sugiu K, et al. Clinical experience and follow-up results. Bone 1999;25(2):11S-15S. DOI: 10.1016/s8756-3282(99)00126-x.

8. Barr M, Barr J. Invitedcommentary. Radiographics 1998;18:320-322.

9. Cotten $\mathrm{A}$, Deramond $\mathrm{H}$, Cortet B. Preoperative percutaneous injection of methyl methacrylate and $\mathrm{N}$-butyl cyanoacrylate in vertebral hemangiomas. Am J Nuclear Res 1996;17(1):137-142.

10. Cotten A, Dewatre F, Cortet B, et al. Percutaneous vertebroplasty for osteolytic metastases and myeloma: effects of the percentage of lesion filling and the leakage of methyl methacrylate at clinical follow-up. Radiology 1996;200(2):525-530. DOI: 10.1148/ radiology.200.2.8685351.

11. Galibert $P$, Deramond $H$, Rosat $P$, et al. Preliminary note on the treatment of vertebral angioma by percutaneous acrylic vertebroplasty. Neurochirurgie 1987;33:166-168.

12. Yuan W-H, Hsu H-C, Lai K-L. Vertebroplasty and balloon kyphoplasty versus conservative treatment for osteoporotic vertebral compression fractures a meta-analysis. Medicine 2016;95(31):e4491. DOI: 10.1097/ MD.0000000000004491. 
13. Ateş A, Gemalmaz HC, Deveci MA, et al. Comparison of effectiveness of kyphoplasty and vertebroplasty in patients with osteoporotic vertebra fractures. Acta Orthop Traumatol Turc 2016;50(6):619-622. DOI: 10.1016/j.aott.2016.10.002.

14. Baerlocher MO, Saad WE, Dariushnia S, et al. Society of interventional radiology standards of practice committee. Quality improvement guidelines for percutaneous vertebroplasty. J Vasc Interv Radiol 2014;25(2):165-170. DOI: 10.1016/j.jvir.2013.09.004.

15. Tsoumakidou G, Too CW, Koch G, et al. CIRSE guidelines on percutaneous vertebral augmentation. Cardiovasc Intervent Radiol 2017;40(3):331-342. DOI: 10.1007/s00270-017-1574-8.

16. Higgins KB, Harten RD, Langrana NA, et al. Biomechanical effects of unipedicular vertebroplasty onintact vertebrae. Spine (Phila Pa 1976) 2003;28(14):1540-1547. DOI: 10.1097/01.BRS.0000076822.61468.7D; discussion 1548.

17. Lamanna A, Maingard J, Kok HK, et al. Vertebroplasty for acute painful osteoporotic vertebral compression fractures: an update. J Med Imaging Radiat Oncol 2019;63(6):779-785. DOI: 10.1111/17549485.12900.

18. Nieuwenhuijse MJ, Bollen L, van Erkel AR, et al. Optimal intravertebral cement volume in percutaneous vertebroplasty for painful osteoporotic vertebral compression fractures. Spine 2012;37(20): 1747-1755. DOI: 10.1097/BRS.0b013e318254871c.

19. Kwon HM, Lee SP, Baek JW, et al. Appropriate cement volume in vertebroplasty: a multivariate analysis with short-term follow-up Korean Neurotrauma 2016;12(2):128. DOI: 10.13004/kjnt.2016.12.2.128.

20. Jin YJ, Yoon SH, Park K-W. The volume tricanalysis of cementin vertebroplasty: Relationship with clinical out comeand complications. Spine 2011;36(12):E761-E772. DOI: 10.1097/BRS.0b013e3181fc914e.

21. Clark W, Bird P, Petal G. Safety and efficacy of vertebroplasty foracute painful osteoporotic fractures (VAPOUR): a multicentre, randomised, double-blind, placebo-controlled trial. Lancet 2016;388(10052): 1408-1416. DOI: 10.1016/S0140-6736(16)31341-1.

22. Jensen ME, Kallmes DF, Short JG, et al., Percutaneous vertebroplasty doesnot increase the risk of adjacent level fracture: aretrospectivestudy (abstr). In: ASNR Annual Meeting Program. Oak Brook, III: American Society of Neuroradiology, 2000;4.

23. Lin EP, Ekholm S, Hiwatashi A, et al. Vertebroplasty: Cement leakage into the disc increases the risk of new fracture of adjacent vertebral body. AJNR Am J Neuroradiol 2004;25(2):175-180.

24. Kallmes DF, Jensen ME. Percutaneous vertebroplasty. Radiology 2003;229(1):27-36. DOI: 10.1148/radiol.2291020222. 